\title{
ADVERSE DRUG REACTION REPORTING PRACTICES BY HEALTH CARE PROFESSIONALS OF KARACHI, PAKISTAN: A QUALITATIVE SURVEY
}

\author{
Sidra Zaheer, (D)Andaleeb Komal, (iD)Ather Akhlaq \\ Department of Health \& Hospital Management, Institute of Business Management, Karachi, Pakistan
}

\begin{abstract}
Background: The safety of medications is of utmost concern for public health. In developed countries, adverse drug reaction reporting systems are well established, but in low-income and middle-income countries such as Pakistan, these are under-developed and ignored. The objective of this qualitative survey was to explore the adverse drug reaction reporting practices by health care professionals of Karachi, Pakistan.

Materials \& Methods: Fifteen health care professionals (HCPs), including physicians, nurses and pharmacists from public, semi-private and private tertiary care hospitals were selected using purposive and snowball sampling for semi-structured interviews. Interviews were digitally recorded, transcribed verbatim, and were analyzed using Thematic Analysis.

Results: The results showed that almost all HCPs have a good understanding of ADR, but did not know the procedures of ADR reporting to the Drug Regulatory Authority of Pakistan (DRAP). Usually, the ADR was manually reported, with few hospitals having an electronic ADR reporting system. Barriers to the ADR reporting included a large influx of illiterate patients, over-burdened staff, lack of financial and technological resources, and ineffective administration. Facilitator to ADR reporting was electronic ADR system.

Conclusion: These findings would help the policymakers and health administrators to revise existing policies and devise new ones for the adoption of adverse drugs reporting (ADR) systems in hospitals.

KEY WORDS: Adverse Drug Reaction; Adverse Drug Reaction Reporting System; Pharmacovigilance; Healthcare; Health Care Professionals; Physicians, Pharmacists; Nurses; Pakistan.

Cite as: Zaheer S, Komal A, Akhlaq A. Adverse drug reaction reporting practices by health care professionals of Karachi, Pakistan: a qualitative survey. Gomal J Med Sci 2021 Jan-Mar; 9(1):3-10. https://doi.org/10.46903/ gjms/19.01.943
\end{abstract}

\section{INTRODUCTION}

1.1 Background: The use of medicines is exponentially increasing due to rise of communicable and non-communicable diseases. The safety of medication is a significant concern for the stakeholders (governments, health care professionals, manufacturers and consumers), emphasizing on the rational use of drugs to improve healthcare services. It is mandatory that the drug must fulfill the criteria of safety, efficacy and quality at the time of registration. ${ }^{1}$ For instance, the United States Food and Drug Administration

\section{Corresponding Author:}

Sidra Zaheer, MBA Student

Department of Health \& Hospital Management

Institute of Business Management

Karachi, Pakistan

E-mail: std_26780@iobm.edu.pk

Date Submitted: $\quad 15-09-2020$

Date Revised: $\quad 12-12-2020$

Date Accepted: $\quad 26-12-2020$
(FDA) is responsible to ensure efficacy, safety, and security of human ${ }^{2}$ and veterinary medicines. Pharmaceutical companies have to pass the four phases clinical trials ${ }^{2}$ of the FDA drug approval process before they start marketing and selling drugs. However, despite the rigorous process of drug development, it is hardly possible to provide complete information on its safety at the time of drug registration. Therefore, a process known as pharmacovigilance (PV) starts as soon as the drug is licensed to use, monitoring its effects by identifying and evaluating any adverse drug reaction (ADR) previously unreported. ${ }^{3}$ ADR is defined by World Health Organization as;

"a response of a drug which is noxious and unexpected, and it is found to happen at prophylactic, diagnostic or therapeutic doses, or at doses of drugs when used for modifying physiological body functions."

ADRs simply are unintended harmful reactions experienced using a single drug or a combination of drugs under normal conditions. ${ }^{5}$ They are considered as 
one of the common reasons for the hospitalization of people, and the foremost reason of morbidity and mortality amongst the hospitalized patients. ${ }^{6}$ In an organized healthcare system, pharmacists and other health care professionals (HCPs) should develop comprehensive guidelines and programs to report ADRs. It is the responsibility of all the healthcare stakeholders, including consumers to report any suspected ADRs through the ADR reporting system. ${ }^{7}$ ADR reporting system, therefore, is essential for improving and enhancing the quality of care. ${ }^{4}$

Using the science of pharmacovigilance, Uppsala Monitoring Centre (UMC) provides operational and scientific support to the WHO Programme for International Drug Monitoring (PIDM). UMC observes and records ADRs in WHO global database, known as VigiBase. ${ }^{8}$ It is the largest database that has received over 20 million ADR reports since 1968 from member countries, including 142 full members and 29 associate members, covering $90 \%$ of the world's population. ${ }^{9}$

PV practices in Pakistan are less well-established than in many other countries. Pakistan is the full member state of WHO PIDM since 2018. ${ }^{10}$ Even the low-income countries such as Liberia and Sudan became members of WHO PIDM before Pakistan. ${ }^{10}$ In 2003, it was stated in the National Drug Policy of Pakistan to develop a PV system, however, it started in $2012^{11}$ after an unfortunate incident happened, when over 200 patients passed away and around 1000 patients were hospitalized in Lahore city of Pakistan due to an ADR caused by a locally manufactured cardiac drug called isosorbide mononitrate (batch number J093). ${ }^{12}$

Hence, the Drug Regulatory Authority of Pakistan (DRAP) was established in 2012 to ensure the quality, availability and safety of therapeutic agents, i.e., drugs and medical equipment in Pakistan. ${ }^{13}$ DRAP together with international regulatory authorities, including WHO and United States Pharmacopeia and Promotion Quality Medicines (USP-PQM) has made a comprehensive framework in order to run a smooth post marketing surveillance of medications in Pakistan. ${ }^{14}$ In 2018, the DRAP launched online ADR reporting system, known as MED Vigilance E-Reporting system, which provides options to health care professionals, patients, consumers, and pharmaceuticals to report ADRs. ${ }^{15}$ Moreover, the DRAP established WEBRADR Med-Safety mobile application to report ADRs. ${ }^{16}$

However, the utilization of these applications has been low so far. ${ }^{17}$ The DRAP has not been able to enforce the regulation strictly. Hardly any hospital in Pakistan has adopted clinical governance systems except a few big names such as Aga Khan Hospital, Karachi and Shaukat Khanam Memorial Cancer Hospital \& Research Centre, Lahore. ${ }^{18}$ Also, the evidence on ADR received from a small number of hospitals is not ample enough to devise and implement drug safety policies. ${ }^{14}$ Therefore, there is a need to investigate ADR reporting practices in tertiary care hospitals and the issues faced by the health care professionals in reporting ADRs.

1.2 Significance: There is a need to know why healthcare professionals do not report ADRs despite many hospitals claiming to have implemented ADR reporting mechanisms and DRAP providing the online portal for reporting ADRs. The outcomes of this study will help the policymakers and managers to facilitate the barriers to ADR reporting in hospitals.

1.3 Objective: The objective of this qualitative survey was to explore the adverse drug reaction reporting practices by health care professionals of Karachi, Pakistan.

\section{MATERIALS AND METHODS}

2.1 Study Design, Setting \& Duration: We undertook this qualitative survey ${ }^{19}$ the from 15 July, 2020 to 05 September, 2020. Ethical approval was taken by the Ethics Review Committee of the Institute.

2.2 Population \& Sampling: The population comprised all health care professionals working in the tertiary care hospitals of Karachi, Pakistan. ${ }^{6}$ Karachi, the capital of Sindh province, is the largest city and a leading financial center of Pakistan. We constructed a sampling matrix of physicians, nurses, and pharmacists working full-time in public, semi-private and private tertiary care hospitals of the city. This also included sampling of respondents likely to hold dissenting views. ${ }^{20}$ We neither recruited any patient nor were any patient data accessed. We used purposive ${ }^{21}$ and snow-ball ${ }^{22}$ sampling techniques and continued recruiting participants until data saturation $^{23}$ had been achieved.

Total 15 health care professionals were interviewed, including four males and 11 females from nine hospitals (private $=9$, public $=9$, and semi-private $=1$ ). The number of physicians, pharmacists and nurses were six, seven and two respectively.

2.3 Data Collection: Respondents were sent an invitation through email to participate voluntarily. The invitation included the information leaflet, consent form and topic guide (see appendix). Due to the corona pandemic, the interviews were conducted using the online platforms (e.g., Google Meet, Zoom), whichever was convenient to the respondents. Interviews on average lasted for 10-15 minutes. The interviews were conducted in English $(n=6)$ and Urdu $(n=9)$ according to the preference of respondents. We recorded field notes for each interview (noting down the technology glitches, respondents' mood and expressions).

2.4 Data Analysis: All interviews' audios were digitally recorded and then transcribed verbatim. Transcripts were checked and stripped of identifiers. 
Coding of data was manually done using MS Word and MS Excel. We kept on doing analysis from the first interview to allow emerging themes to revise the topic guide for successive interviews and to identify the negative cases to ensure the robustness of the study. ${ }^{24}$ Data analysis was conducted using the combination of deductive and inductive analysis. A deductive analysis was informed by the work of Hussain, et al., ${ }^{14}$ while new themes emerged from the data using a inductive approach.

\section{RESULTS}

3.1 Demographics: Total 15 health care professionals were interviewed, including four males and 11 females from nine hospitals (private $=9$, public $=9$, and semi-private $=1$ ). The number of physicians, pharmacists and nurses were six, seven and two respectively. Working experience of 1-5 years was reported by 13 participants, while $6-10$ years working experience was reported by 2 participants. The background of participants is given in Table 3.1.

Participants when asked about the ADR reporting practices in their health-care organizations, Out of 15 respondents, two of the physicians from the public hospitals stated that no system of ADR reporting existed in their organization. Ten participants (public $=5$, private $=4$, semi-private $=1$ ) from all the three professions stated that ADR reporting has been done manually in their organization, whereas three participants (two nurses and one pharmacist) from private hospitals reported the existence of online reporting system in their healthcare facility.
Two themes evolved out from the data namely, (1) Knowledge and current practices of ADR reporting, (2) Barriers and facilitators to implement ADR reporting system.

\subsection{Knowledge and current practices of ADR reporting}

Almost every respondent was well informed about the concept of ADR and PV but majority of them (nurses and physicians) were unaware of the national regulating body; DRAP, and didn't know about the procedures and processes of ADR data collection and reporting.

"Any unwanted or harmful reaction caused by the use of a medical product which could be life threatening for the patient." (HCP-3)

"ADR is a broad term which may include dangerous or unwanted effects of a drug. It can be dose related; administration technique related etc., which could manifest in the form of allergies and other symptoms." (HCP-14)

"I am unaware of any regulatory body for reporting any ADR existing in Pakistan and if it exists, it is unpopular among us, including senior or junior doctors." (HCP-2)

"In my knowledge, DRAP is controlling the reporting system. It has initiated the PV in Pakistan to monitor the ADR caused by different drugs, so that complete data could be collected through this reporting. But it is in the infancy phase. It has PV centers in different areas, but they are in developing phase as well." (HCP-7)

Table 3.1: Background of participants in a qualitative survey exploring adverse drug reaction reporting practices by health care professionals of Karachi, Pakistan $(n=15)$

\begin{tabular}{|l|c|c|c|}
\hline S. No. & Profession & Hospital's Type & ADR Reporting System \\
\hline HCP-1 & Physician & Public & No system \\
\hline HCP-2 & Physician & Public & Manual \\
\hline HCP-3 & Pharmacist & Private & Manual \\
\hline HCP-4 & Nurse & Private & Online \\
\hline HCP-5 & Physician & Public & Online \\
\hline HCP-6 & Nurse & Private & Manual \\
\hline HCP-7 & Pharmacist & Semi Private & Manual \\
\hline HCP-8 & Physician & Public & No system \\
\hline HCP-9 & Physician & Public & Manual \\
\hline HCP-10 & Pharmacist & Public & Manual \\
\hline HCP-11 & Physician & Public & Manual \\
\hline HCP-12 & Pharmacist & Private & Online \\
\hline HCP-13 & Pharmacist & Private & Manual \\
\hline HCP-14 & Pharmacist & Private & Manual \\
\hline HCP-15 & Pharmacist & Private & \\
\hline
\end{tabular}


Further, all the respondents stated that whenever they encountered ADR, they usually halted the suspected drug and treated the patient using symptomatic therapy.

"Stop the suspected drug immediately and provide symptomatic treatment to the patient. For example: in case of chills, fever or rashes; treat accordingly, or give anti-allergic or even anti-dote, in case if it is available in the hospital." (HCP-1)

"If we get approached by a patient with an ADR, we first treat the patient with the preferred and required treatment. For Example: if a patient develops an ADR with an antibiotic, we usually administer anti-allergic to counter off the hypersensitivity reaction." (HCP-7)

"There is no reporting system existing as per my knowledge in my organization. Further if there occurs any adverse drug reaction, we treat the patient accordingly." (HCP-1)

"We have an online reporting system in our organization, through which we have to report any such incident within 24-48 hours of its occurrence." (HCP-4)

"We have actually developed an ADR form, the yellow form. It is developed according to international guidelines and keeping in mind the PV program of DRAP. These forms are required to be filled by HCP within 24-48 hours of ADR occurrence, then these filled forms are submitted to the Drug Information Center of Pharmacy for further evaluation." (HCP-7)

Finally, all the respondents reported that ADR reporting can help improve the quality of healthcare, create new knowledge, and allow practitioners and patients to make evidence-based decisions.

'Of course, patients' quality of life will be improved by reporting of ADR. Perhaps some of the reactions are life threatening, so on the basis of available information and reports we will get help in future as well if we come across with such situation again." (HCP-4)

"Yes, definitely. Because if we report these ADRs, we get to know the causes and reasons that trigger them. For example, hypersensitivity reaction occurs due to the administration of ceftriaxone at higher doses, such type of knowledge and pattern can be known through reporting of ADR only." (HCP-10)

\subsection{Barriers and Facilitators to ADR reporting system}

The majority of the HCPs from both private and public hospitals reported many barriers that caused the under-reporting of ADRs in their organization. These included lacks of funding, a large influx of patients, over-burdened staff, lack of awareness of ADR reporting, lack of technology, illiterate patients, shortage of space in hospitals, manually recording ADRs and not reporting to DRAP, and ineffective administration.

"In government sector it is quite difficult to establish any such system due to number of barriers, such as lack of funding, unavailability of proper facilities like patients don't even have easy access to the medicine, increased patients' burden on the HCP, overcrowded spaces with patients, communication barrier with the patients' attendants due to lack of education and patient themselves are illiterate, which itself is a barrier. They (patients) usually don't know that obnoxious affect had occurred which should be treated." (HCP-1)

"Lack of knowledge within different organizations is the biggest barrier. Some HCP are not even aware about ADR reporting, so yes unawareness is a big gap that needs to be filled priory." (HCP 05)

"Shortage of staff, ineffective administration technique, over burdening and increase of patient influx due to which health care professionals usually ignore the protocols. Also, technology barrier is one of the reasons in hindering the implementation of reporting system as staff is usually not well trained." (HCP-10)

"I think the main barrier in our system is manual reporting, there is no concept of record maintenance on weekly or monthly basis. And also, manual reports data is not sent to any regulatory authority like DRAP so that they can record and gather the information about new unwanted effects produced by drug and update the knowledge in their database." (HCP-14)

On the contrary, some HCPs suggested facilitators to the adoption of the ADR reporting. For example, a female nurse and a male physician from private hospitals; and a female physician from the public hospital suggested raising awareness of ADR reporting among HCPs. Further, a female pharmacist from a semi-private hospital suggested introducing electronic ADR reporting in place of manual ADR reporting. Also, a female pharmacist from a private hospital suggested integrating Computerized Physician Order Entry (CPOE) with the ADR system.

"The ADR form/ questionnaire must be the part of patient's file, either provided by the regulatory bodies or the pharmaceutical company itself. Doctors usually don't have much time to separately report adverse drug reactions, so a quick form/questionnaire should be available right away to report adverse reactions. Furthermore, both pharmacist and pharmacy department are a backbone to an ADR as they are the major awareness generators. Therefore, greater ratio of pharmacist should be included in the hospital settings." (HCP-2)

"First suggestion is that we (as HCP) should always make sure that all ADRs are reported. Secondly, we have to develop a software as an online system so that ease of reporting can be increased. Foremost, is to develop the awareness. We have to carry out sessions on introducing different ADRs to our healthcare team, the importance of ADR reporting and how they can essentially impact the quality of care they are giving to the patient." (HCP-7)

"As far as inpatient practices are concerned, there is 
such strict check and balance that hardly any ADR gets unreported, but since being an outpatient pharmacist, I have experienced that once patient gets medicine from pharmacy, we have no idea what has happened to them. Either they get cured or experienced any un-desirable effects. We do have Drug and Poison Information System, where patient can report and inquire about drugs, but sometimes such reporting is not enough. I think we should develop a proper online reporting system for outpatient settings also. Moreover, I suggest to develop an integration between the current $A D R$ and the CPOE system as this would help in tracking the patient's ADR history." (HCP 13)

Moreover, one female pharmacist from a private hospital reported that hardly any adverse drug event was overlooked because of the highly efficient ADR system deployed at her hospital,

"As in my organization, the system is so robust that rarely it happens when an ADR goes unnoticed. But if it does happen it might be due to maintaining the reputation and status of organization. Otherwise, it is not a common practice to hide or not to report the $A D R$, we have different activities that we do on daily basis in order to check the ADR due to any drug and if found anything, being a pharmacist, we inquire about it and report if not yet reported. So, yes if there is underreporting of ADR, it may be due to certain political concerns only." (HCP-13)

Finally, a male physician from a public hospital recommended that DRAP can help to effectively implement the ADR reporting within the hospitals. He perceived that DRAP should facilitate hospitals by providing an adequate channel of reporting ADRs, for instance, by providing contact details of their representatives to the hospitals.

"An access to DRAP is the main thing should be focused on, there should be proper channel for the reporting of ADR. DRAP should provide proper representatives, proper email address for reporting, so that ADR can be minimized and that's how we can create an impact on the lives of human beings." (HCP 05)

\section{DISCUSSION}

\subsection{Statement of Principal Findings}

This study highlighted the current practices of reporting ADR and identified barriers and facilitators to implement ADR reporting system in tertiary care hospitals. Although all health care professionals were aware of the concept of ADR reporting, however, majority of them were unfamiliar of DRAP and its PV activities. The ADRs were reported manually and electronically in some hospitals, whereas, there were few who did not report at all. Increased patients' influx, lack of awareness, lack of resources (funds and technology), manual ADR recording system, ineffective administration, overcrowded space, over-burdened staff, and illiterate patients were the barriers reported, whereas, raising awareness of
ADR reporting, introducing online ADR in place of manual $A D R$, availability of integrated CPOE and ADR system, and need to establish easy access to DRAP representatives were reported as facilitators to the deployment of ADR reporting system.

\subsection{Strengths and Limitations}

The strengths included conducting study in the largest metropolitan city and a leading financial hub of Pakistan, including different types of health care professionals, such as doctors, nurses and pharmacists responsible to monitor and report adverse events, recruiting and interviewing until data saturation, ${ }^{23}$ giving attention to negative cases, ${ }^{25}$ and using the combination of inductive and deductive analysis. ${ }^{25}$

The limitations included missing health care professionals' views from other cities of Pakistan, and the concerns about the transferability of result. Nevertheless, findings can be generalized to an extent but not completely due to the different policies and healthcare infrastructure in other provinces of Pakistan. However, results can also be applicable on other low-income and middle-income countries having similar demographics and income. Also, more nurses should have been included but due to the hard times of COVID pandemic, it was difficult to contact them and get their views.

\subsection{Interpreting Findings with the Existing Literature}

Contrary to our results in which physician, pharmacist and nurses have some knowledge about PV systems and the activities of DRAP, a study conducted by Furqan and his colleagues ${ }^{26}$ in Lahore, Pakistan to evaluate the knowledge, attitude, practices and perceptions of health care professionals regarding ADR reporting and monitoring, found that physicians and nurses, except pharmacists, were hardly aware of $P V$ and ADR practices.

Similarly, another study which was conducted in Lahore, Pakistan by a group of pharmacists ${ }^{14}$ taking interviews of the hospital pharmacists to explore their knowledge, attitude and practices towards the ADR system found that hospital pharmacists had good understanding of medication safety and ADR reporting but unfortunately, they did not practice it. The study highlighted a communication gap between the regulatory authorities and health care professionals, despite setting up of drug safety policies such as alert on medication by the Provincial Drug Control Unit Punjab (PDCUP).

Further, a cross-sectional study in Pakistan on HCPs (physicians and pharmacists) to assess the knowledge, attitudes, and practices of ADR found that the pharmacists were more aware (47.1 percent vs. 13.8 percent at $p<0.001$ ) (similar to our study findings) and have more positive attitude ( 97.1 percent vs. 76.3 percent at $p<0.001$ ) about ADR than the physicians. ${ }^{27}$ 
Similarly, a recent study conducted in Lahore, Pakistan ${ }^{28}$ involved interviewing nurses to know their perspectives about ADR, showed that although the nurses knew about the ADR reporting, it was their common practice not to report any ADRs. Reasons for not reporting ADRs were the excessive burden of work on HCPs, and the lack of knowledge and training to execute and implement ADR reporting in their healthcare organization.

Our findings also go parallel with the international studies. For example, randomized nested trial was conducted in Bulgaria to evaluate the physicians' knowledge and attitude towards ADR. The findings showed unfamiliarity of physicians with the PV system, however, the education intervention (provision of reading material to the physicians after one month of the first survey), showed a positive attitude and improved physicians' knowledge on the ADR. ${ }^{29}$

Several barriers to the implementation of ADR reporting system in hospitals were found in our study. One of the foremost barrier was the excessive workload of HCPs that was also identified in the studies conducted in Northern Cyprus, Riyadh, Saudi Arabia \& New South Wales. ${ }^{30-31}$ This barrier can be addressed by increasing the workforce in hospitals.

Furthermore, the scarcity of knowledge on the significance of PV and ADR reporting amongst the HCPs has been observed in other studies such as a study in Lagos, Nigeria where only one physician out of the 120 respondent doctors reported to receive the training on how to report the ADR. ${ }^{32}$

It was interesting to know through our research findings that HCPs including physicians and nurses are realizing the significant role of pharmacists and the pharmacy department in provision of quality and safe pharmaceutical care to the patients. It is in accordance with findings of a study conducted in Cuba where both nurses and physicians approached pharmacists for taking advice on management of drugs \& recording of ADRs. ${ }^{33}$

Globally, in developed countries, the ADR reporting has shifted from prescribers to customers or patients. However, the ADR reporting program is still in its initial phase in under developed countries including Pakistan. ${ }^{34}$

\subsection{Implications of findings for Practice, Policy and Research}

The DRAP, although, has introduced the online reporting system, many of the health care professionals were still not aware of it. Also, the DRAP should revise its online form to make it more precise and friendly, as currently, its lengthiness is deviating HCPs and patients from reporting ADRs. The DRAP also needs to modify the online form to keep the information private and confidential of the health care professionals reporting ADRs. ${ }^{10}$
The reporting of ADR incidents is low despite the established online platform by DRAP for reporting adverse events. ${ }^{10}$ The policymakers, including the state health ministry representatives, need to enforce hospitals to use the standardized national monitoring and reporting framework for ADRs. Awareness sessions and training should be provided to HCPs on how to report ADR. These should also be made part of the curriculum of HCPs. Finally, as healthcare quality varies between rural and urban areas, future research on the rural healthcare sector may give novel insights on PV and ADR reporting of hospital and HCPs.

\section{CONCLUSION}

Almost all the health care professionals (HCPs) were well aware of the adverse drug reaction (ADR) reporting system and its reporting. The majority of the hospitals have a manual ADR system, while only a few of them report electronically. Despite many barriers such as lack of finance, large influx of patients, and ineffective administration, ADR reporting in hospitals can be facilitated by raising awareness of ADR reporting among HCPs, digitizing the ADR reporting, and giving easy access to HCPs to contact Drug Regulatory Authority of Pakistan (DRAP) representatives. The findings of this study will be helpful for the policymakers, healthcare managers and DRAP to devise policies for the deployment and adoption of ADR systems in hospitals based on the current practices of ADR reporting and its barriers.

\section{Appendix (Interview Guide)}

1. What is your understanding of Adverse Drug Reaction?

2. Are you aware about the existence of the regulatory body that regulates ADR reporting in Pakistan?

3. What would you do if you were approached by a patient with a severe ADR (any recent incidence, what was your strategy to deal with the patient)?

4. Do you have any guidance on reporting or how to when to and where to report any ADR in your organization?

5. Do you think that ADR reporting will influence the quality of life of the patients under your care?

6. In your opinion, what are the possible factors that contribute as the barriers to ADR reporting in your organization?

7. What could be the possible suggestions to improve ADR reporting (in your hospital) in future? Any suggestions?

\section{REFERENCES}

1. Shakeel S, Iffat W, Anjum F, Bushra R, Ibrahim S, Shafiq S. Emerging need of pharmacovigilance: Perspectives of future pharmacist in Pakistan. Int J Pharm Teach Pract 2014;5(2):6. 
2. Safety Report Updates | FDA [Internet]. [cited 2020 Sep 10]. Available from: https://www.fda. gov/science-research/pediatrics/safety-report-updates

3. Organization WH. Pharmacovigilance: ensuring the safe use of medicines 2004 [cited 2020 Sep 10]; Available from: https://apps.who.int/iris/ handle/10665/68782

4. Nisa ZU, Zafar A, Sher F. Assessment of knowledge, attitude and practice of adverse drug reaction reporting among healthcare professionals in secondary and tertiary hospitals in the capital of Pakistan. Saudi Pharm J 2018 May; 26(4):453-61. https://doi.org/10.1016/j.jsps.2018.02.014

5. Coleman JJ, Pontefract SK. Adverse drug reactions. Clin Med (Lond). 2016 Oct;16(5):481-5. https://doi.org/10.7861/clinmedicine.16-5-481

6. Smith FJ. Research methods in pharmacy practice. 1st ed. London: Pharmaceutical Press; 2002.

7. ASHP guidelines on adverse drug reaction monitoring and reporting. American Society of Hospital Pharmacy. Am J Health Syst Pharm 1995 Feb 15;52(4):417-9. https://doi.org/10.1093/ ajhp/52.4.417

8. Uppsala Monitoring Centre. WHO Collaborating Centre for International Drug Monitoring. Privacy policy [Internet]. [cited 2020 Sep 10]. Available from: https://www.who-umc.org/about-us/privacy-policy/

9. Uppsala Monitoring Centre. WHO Collaborating Centre for International Drug Monitoring. Members of the WHO Programme for International Drug Monitoring [Internet]. [cited 2020 Sep 5]. Available from: https://www.who-umc.org/global-pharmacovigilance/who-programme-for-international-drug-monitoring/who-programme-members/

10. DRAP 2019. Pakistan National Pharmacovigilance Guidelines (Draft). Islamabad, Pakistan: Drug Regulatory Authority of Pakistan [Internet]. [cited 2020 Sep 10]. Available from: https://dra.gov.pk/ docs/Draft\%20Pakistan\%20National\%20Pharmacovigigilance\%20guidlines\%204-9-2019.pdf

11. Atif $M$, Ahmad $M$, Saleem $Q$, Curley L, Qamar-uzZaman M, Babar ZUD. Pharmaceutical policy in Pakistan. In: Pharmaceutical Policy in Countries with Developing Healthcare Systems. Springer; 2017. p. 25-44. https://doi.org/10.1007/978-3319-51673-8 3

12. WHO | Deadly medicines contamination in Pakistan [Internet]. WHO-2013. World Health Organization; 2013 [cited 2020 Sep 1]. Available from: https://www.who.int/features/2013/pakistan medicine safety/en/

13. Drug Regulatory Authority of Pakistan, Ministry of National Health Services, Regulations \& Coordination, Islamabad [Internet]. Pharmacy Services Division 2020 [cited 2020 Sep 1]. Available from: http://dra.gov.pk/Home/PharmacyServicesDivision

14. Hussain R, Hassali MA, Hashmi F, Farooqui M.
A qualitative exploration of knowledge, attitudes and practices of hospital pharmacists towards adverse drug reaction reporting system in Lahore, Pakistan. J Pharm Policy Pract 2018 Dec;11(1):16. https://doi.org/10.1186/s40545-018-0143-0

15. WHO-UMC. MED Vigilance E-Reporting System [Internet]. WHO-UMC 2020 [cited 2020 Aug 11]. Available from: https://primaryreporting.whoumc.org/Reporting/Reporter?OrganizationID=PK

16. Drug Regulatory Authority of Pakistan, Ministry of National Health Services, Regulations \& Coordination, Islamabad [Internet]. DRAP 2020 [cited 2020 Aug 17]. Available from: https://www.dra. gov.pk/Home/DownloadsAllDocs\#gsc.tab $=0$

17. Kiani A. Drug monitoring. Dawn 2019 Feb 24 [cited 2020 Sep 12]. Available from: https://www. dawn.com/news/1465733/drug-monitoring

18. IClJ's global probe: Defective medical devices causing death, disability [Internet]. [cited 2020 Aug 12]. Available from: https://www.thenews. com.pk/print/398620-icij-s-global-probe-defective-medical-devices-causing-death-disability

19. Crowe S, Cresswell K, Robertson A, Huby G, Avery $A$, Sheikh $A$. The case study approach. BMC Med Res Methodol 2011;11(1):1-9. https:// doi.org/10.1186/1471-2288-11-100

20. Patton MQ. Qualitative evaluation and research methods. 2nd ed. Los Angeles: SAGE Publications; 1990.

21. Palinkas LA, Horwitz SM, Green CA, Wisdom JP, Duan N, Hoagwood K. Purposeful sampling for qualitative data collection and analysis in mixed method implementation research. Adm Policy Ment Health 2015 Sep;42(5):533-44. https://doi. org/10.1007/s10488-013-0528-y

22. Browne K. Snowball sampling: using social networks to research non-heterosexual women. Int J Soc Res Methodol 2005;8(1):47-60. https://doi. org/10.1080/1364557032000081663

23. Guest G, Bunce A, Johnson L. How many interviews are enough? an experiment with data saturation and variability. Field Methods 2006;18(1):5982. https://doi.org/10.1177/1525822X05279903

24. Greenhalgh T, Robert G, Macfarlane F, Bate P, Kyriakidou O. Diffusion of innovations in service organizations: systematic review and recommendations. Milbank Q. 2004;82(4):581-629. https:// doi.org/10.1111/j.0887-378X.2004.00325.x

25. Pope C, Ziebland S, Mays N. Qualitative research in health care. Analysing qualitative data. BMJ 2000;320(7227):114-6. https://doi.org/10.1136/ bmj.320.7227.114

26. Hashmi F, Khan SM, Qureshi S, Malik UR, Atif N, Saleem F. Assessment of knowledge, attitude and practices of healthcare professionals towards adverse drug reactions monitoring and reporting: a cross-sectional study in Lahore, Pakistan. Mod Care J 2020; 17(3);e104827. https://doi. org/10.5812/modernc. 104827

27. Nisa ZU, Zafar A, Zafar F, Pezaro S, Sher F. Adverse drug reaction monitoring and reporting 
among physicians and pharmacists in Pakistan: a cross-sectional study. Current Drug Safety 2020;15(2):137-46. https://doi.org/10.2174/1574 886315666200427120322

28. Hussain R, Hassali MA, Ur Rehman A, Muneswarao J, Atif M, Babar ZU. A qualitative evaluation of adverse drug reaction reporting system in Pakistan: findings from the nurses' perspective. Int J Environ Res Public Health 2020 Apr 27;17(9):3039. https://doi.org/10.3390/ijerph17093039

29. Stoynova V, Getov IN, Naseva EK, Lebanova HV, Grigorov EE. Physicians' knowledge and attitude towards adverse event reporting system and result to intervention-randomized nested trial among Bulgarian physicians. Med Glas (Zenica) 2013 Aug;10(2):365-72. PMID: 23892860.

30. Toklu HZ, Soyalan M, Gültekin O, Özpolat M, Aydın MD, Günay AC. The knowledge and attitude of the healthcare professionals towards pharmacovigilance and adverse drug reaction reporting in northern Cyprus. J Pharmacovigilance 2016;4:193. https://doi.org/10.4172/23296887.1000193
31. Aljadhey H, Mahmoud MA, Alshammari TM, AlDhaeefi M, Le Louet H, Perez-Gutthann S, et al. A qualitative exploration of the major challenges facing pharmacovigilance in Saudi Arabia. Saudi Med J 2015;36(9):1097. https://doi.org/10.15537/ smj.2015.9.12125

32. Oshikoya KA, Awobusuyi JO. Perceptions of doctors to adverse drug reaction reporting in a teaching hospital in Lagos, Nigeria. BMC Clin Pharmacol 2009 Aug 11;9:14. https://doi. org/10.1186/1472-6904-9-14

33. Dupotey Varela NM, Oliveira DR de, Sedeño Argilagos C, Oliveros Castro K, Mosqueda Pérez E, Hidalgo Clavel $\mathrm{Y}$, et al. What is the role of the pharmacists, physicians' and nurses' perspectives in community and hospital settings of Santiago de Cuba. Braz J Pharm Sci 2011 Dec;47(4):709-18. https://doi.org/10.1590/S198482502011000400007

34. Inácio P, Cavaco A, Airaksinen M. The value of patient reporting to the pharmacovigilance system: a systematic review. Br J Clin Pharmacol 2017 Feb;83(2):227-46. https://doi.org/10.1111/ bcp. 13098

CONFLICT OF INTEREST
Authors declare no conflict of interest.
GRANT SUPPORT AND FINANCIAL DISCLOSURE
None declared.

\section{AUTHORS' CONTRIBUTION}

The following authors have made substantial contributions to the manuscript as under:

$\begin{array}{ll}\text { Conception or Design: } & \text { SZ, AK, AA } \\ \text { Acquisition, Analysis or Interpretation of Data: } & \text { SZ, AK, AA } \\ \text { Manuscript Writing \& Approval: } & \text { SZ, AK, AA }\end{array}$

All the authors agree to be accountable for all aspects of the work in ensuring that questions related to the accuracy or integrity of any part of the work are appropriately investigated and resolved. 